\title{
Think twice before stent insertion for renal artery aneurysm with elusive etiology: a case report
}

\author{
Jian-zhong Zhang ${ }^{1} \mathbb{D}$, Peng Zhang ${ }^{1} \mathbb{D}$, Li-yang Wu ${ }^{1} \mathbb{D}$, Yong Wang ${ }^{1} \mathbb{D}$, Kun Gao ${ }^{2}$, Qiang Huang ${ }^{2^{*}}$ (D) and \\ Xiao-hui Wang ${ }^{3}$ (D)
}

\begin{abstract}
Background: Endovascular treatment has been recognized as the first line therapy for renal artery aneurysm (RAA). However, RAA related with malignancies had been sporadically reported in the literature. Stent insertion should be contraindicated for RAAs with malignant etiology, whereas surgery be optimal.

Case presentation: A 40-year-old female underwent covered stent insertion to exclude the left RAA for suspected Takayasu arteritis in a reginal hospital. Three months later the RAA recurred with sign of threatened rupture, and the patient was transferred for salvage embolization with coils and thrombin injection. However, 20 days after the embolization procedure, multiple painful subcutaneous nodules developed in her flanks. Undifferentiated sarcoma was revealed by the pathological biopsy of the nodules. The RAA in this case was most likely related with the malignancy.

Conclusion: Malignancy was the most likely etiology behind recurrent aneurysm in this case. Definite diagnosis is mandatory for interventional radiologists before stent insertion for treatment of RAA.
\end{abstract}

Keywords: Renal artery aneurysm (RAA), Stent insertion, Embolization, Undifferentiated sarcoma

\section{Background}

Renal artery aneurysm (RAA) is one of the most common visceral artery aneurysms, requiring treatment because of the high risk of rupture [1]. Surgery repair of RAA is often complex and technically challenging, with some may even require nephrectomy. Endovascular treatment has been recognized as the first line therapy for RAA [2, 3]. However, RAA related with malignancies had been sporadically reported in the literature $[4,5]$. Stent insertion should be contraindicated for RAAs with malignant etiology, whereas surgery be optimal. Here we present a case of recurrent RAA after prior covered stent insertion, with elusive etiology. Salvage embolization had to be performed with the sacrifice of the left kidney. Multiple subcutaneous nodules developed, and pathological biopsy revealed undifferentiated sarcoma.

\footnotetext{
* Correspondence: hq0713@163.com

${ }^{2}$ Department of Interventional Radiology, Beijing Chaoyang Hospital, Capital Medical University, Beijing, China

Full list of author information is available at the end of the article
}

\section{Case presentation}

A 40-year-old female was initially admitted into a regional hospital for the left flank pain and refractory hypertension. Ultrasound and computed tomography (CT) revealed severe stenosis in the right renal artery and aneurysm in the left (Figs. 1 and 2). The diagnosis of Takayasu arteritis was assumed, but without evidence from either lab tests or images. Endovascular bilateral renal artery stenting was performed, with uncovered stent inserted in the right renal artery and covered one in the left (Figs. 3 and 4). A stenosis distal to the covered stent in the left renal artery was noted and could be the potential cause of recurrence (Fig. 3). The symptoms ameliorated after the interventional therapy. However, three months later the symptom of left flank pain recurred, and repeated CT showed relapse of the left RAA. Expectant treatment was ineffective, so the patient was transferred to our Urology Surgery Department. The patient complained about fatigue and intermittent dull pain in her left flank. But general condition was moderate. Multidisciplinary consultation was organized following

(c) The Author(s). 2019 Open Access This article is distributed under the terms of the Creative Commons Attribution 4.0 International License (http://creativecommons.org/licenses/by/4.0/), which permits unrestricted use, distribution, and reproduction in any medium, provided you give appropriate credit to the original author(s) and the source, provide a link to the Creative Commons license, and indicate if changes were made. The Creative Commons Public Domain Dedication waiver (http://creativecommons.org/publicdomain/zero/1.0/) applies to the data made available in this article, unless otherwise stated. 


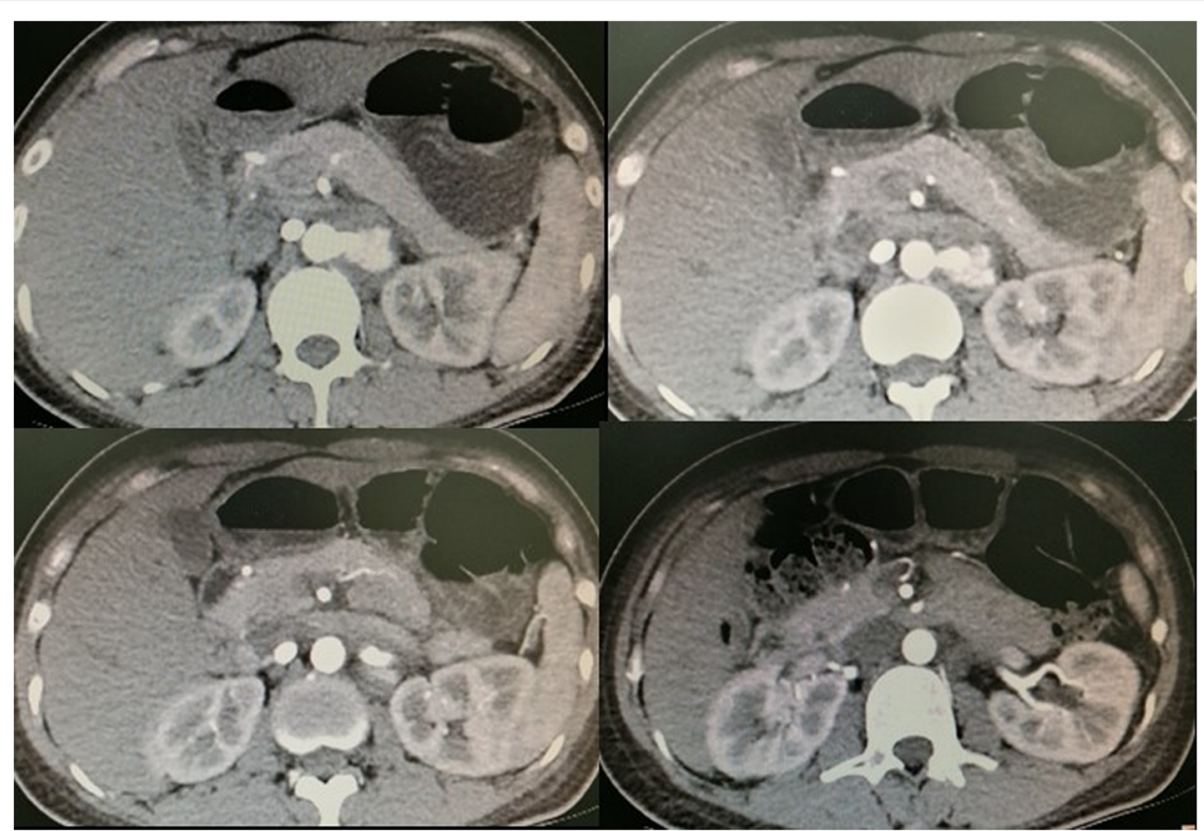

Fig. 1 Computed tomography (CT) revealed aneurysm in the left renal artery

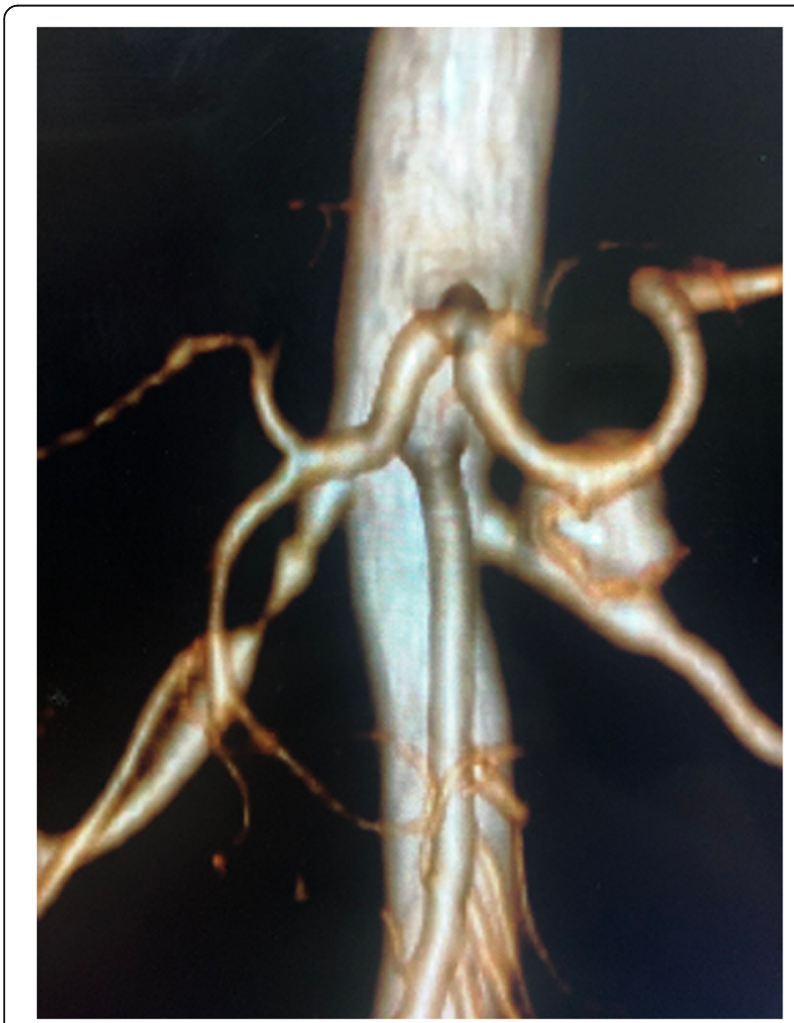

Fig. 2 Pre-procedural Reconstructed CT showed the stenosis in the right renal artery and aneurysm in the left the admission of the patient in our center. The size of the aneurysm (over $30 \mathrm{~mm}$ in diameter) and progressive pain gave the impression of a threatened rupture. Given the giant size of the aneurysm, previous covered stent implantation history, and the elusive etiology, immediate radical nephrectomy was considered, however, the left covered renal artery stent stretched into the aorta was a great challenge for surgery (Figs. 3 and 4). She was transferred to the interventional radiology suite for endovascular treatment. Written informed consent was obtained. Under local anesthesia, access from the right groin was obtained and a $5 \mathrm{~F}$ sheath was placed.

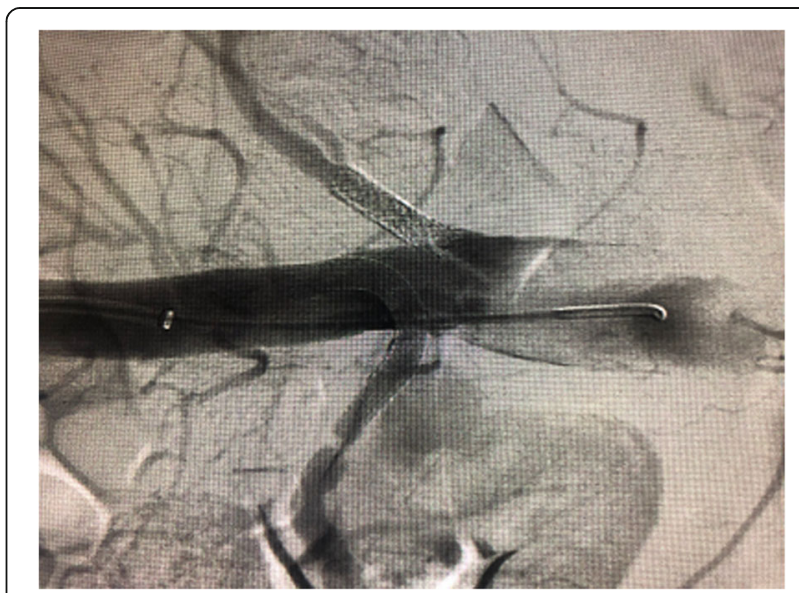

Fig. 3 Complete angiography during the first interventional procedure showed the bilateral stents. A stenosis was noted distal to the covered stent in the left renal artery 


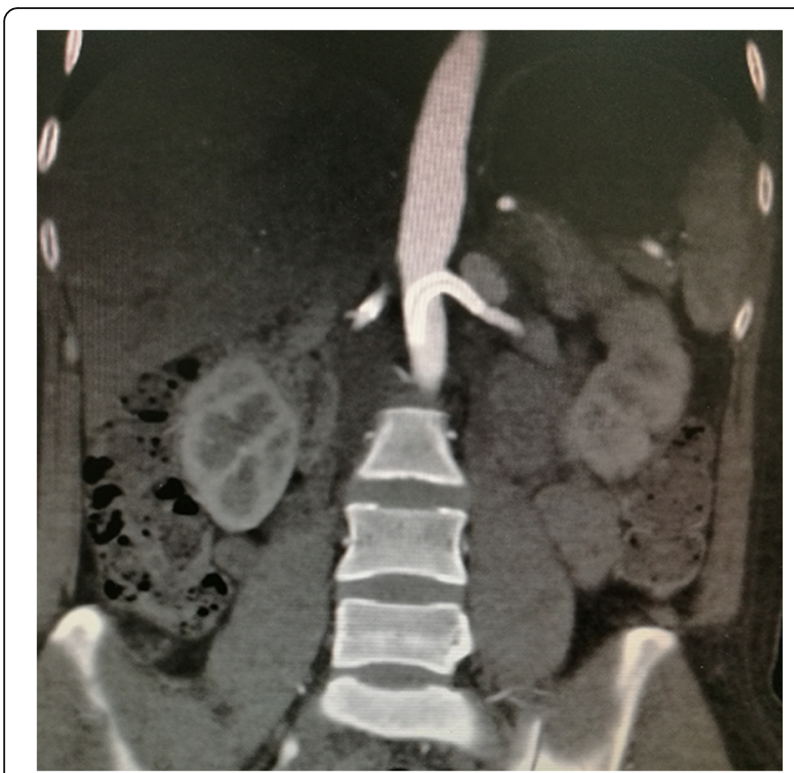

Fig. 4 Reconstructed $\mathrm{CT}$ revealed the left covered renal artery stent stretching into the aorta

Angiography showed the bilateral renal artery stent insertion, and the presence of a large aneurysm originating from the distal end of the left renal artery stent (Fig. 5a). The stent was a covered one and the proximal part of it stretched into the aorta. A $6 \times 40 \mathrm{~mm}$ balloon catheter (ATB advance, Cook, Bloomington, IN, USA) was placed into the stent through a guide wire (Terumo, Tokyo, japan). Thrombin injection was completed under protection of the balloon dilation (Fig. 5b). Further embolization with 2 coils placed into the prior stent $(10 \mathrm{~mm}$, Boston Scientific, Interlock) successfully occluded the aneurysm, with sacrifice of the left kidney (Fig. 5c).

The one-week post-embolization renal function tests (BUN and CREA) were within normal range. The patient remained stable after the second endovascular treatment and was discharged. However, the patient developed multiple painful subcutaneous nodules in her flanks 20 days after the embolization procedure. Biopsy was performed in the regional hospital and pathological exam revealed undifferentiated sarcoma (Fig. 6). Chemotherapy was tried but the patient could not tolerate it. The patient experienced more episodes of hemorrhagic shock which required multiple blood transfusions, and finally passed away 2 more weeks later.

\section{Discussion and conclusion}

RAA rupture is a critical clinical situation and requires emergency management. Surgery is limited for the deep vascular anatomy and poor vision. Varied endovascular approaches including embolization coils, covered stent grafts, flow-diverting stents, vascular plugs, thrombin or liquid embolic agents have been reported [2]. A covered stent may be the appropriate and reliable choice for the treatment of a ruptured RAA, with advantage of kidney preservation. However, stent implantation was not a good choice for RAA with malignant etiology. Surgery was contraindicated due to the prior covered stent when the RAA recurred in this case, the salvage embolization only delayed the rupture of the aneurysm. Multiple blood transfusions during the follow up indicated further hemorrhage from the aneurysm rupture occurred. We had decided to embolize the left renal artery only after a detailed discussion with the urologists in our center. Nephrectomy was proposed, but the risk of failing to ligate the left renal artery or relapse of aneurysm in the proximal part of the ligation was great, because of the prior inserted stent. Hemorrhage and exudation from the aneurysm could pose technical difficulty to expose renal hilar. Therefore, embolization with coils and thrombin injection surely was not the optimal choice, but the safest and simplest one in the situation.

For this case, the oversizing of the covered stent (Fig. 3) might be one of the culprits for recurrence of the aneurysm. The length of the stent was also not well

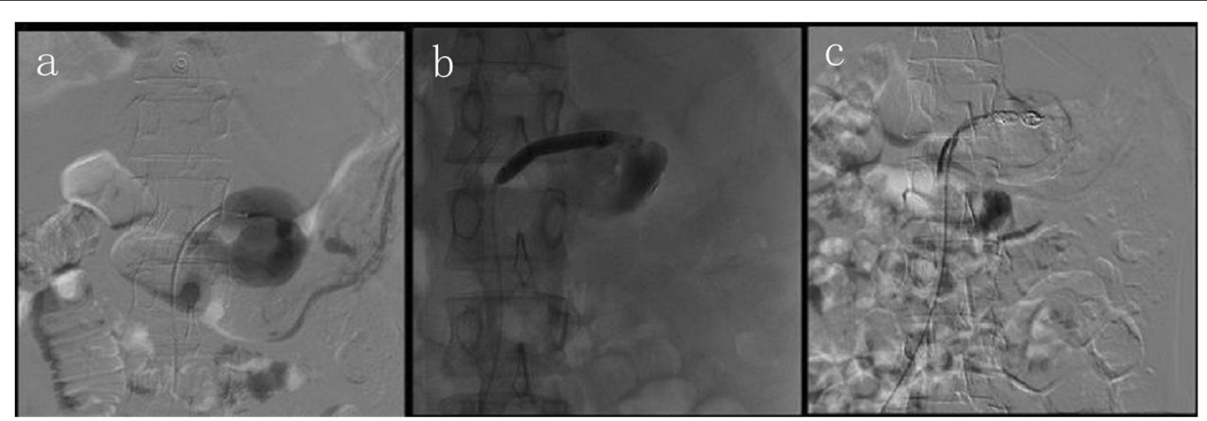

Fig. 5 Angiography showed the bilateral renal artery stent insertion, and the presence of a large aneurysm originating from the distal end of the left renal artery stent (a). A $6 \times 40 \mathrm{~mm}$ balloon catheter was placed into the stent, and thrombin injection was completed under protection of the balloon dilation (b). Further embolization with 2 coils placed into the stent (10 mm, Boston Scientific, Interlock) successfully excluded the aneurysm, confirmed by the angiography check of the left renal artery (c) 


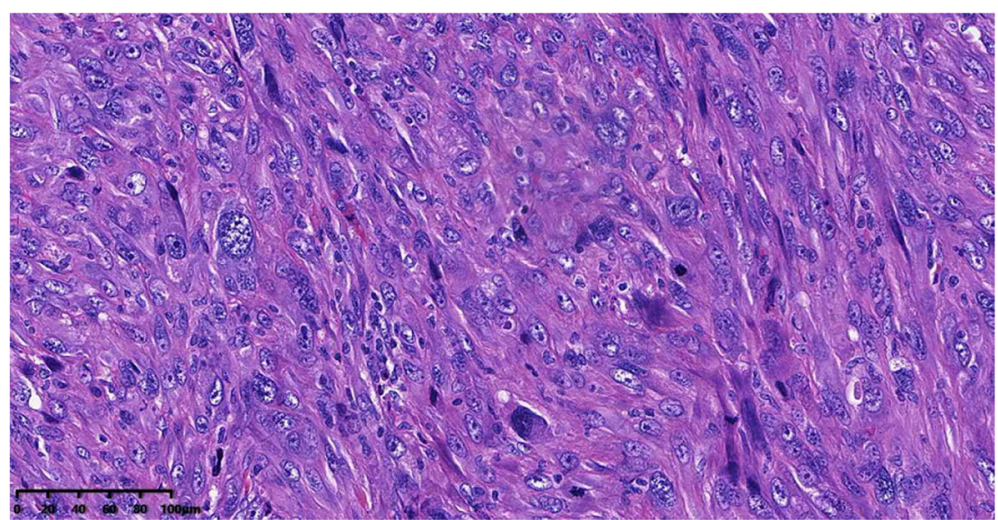

Fig. 6 Microscopic examination of the tumor. Spindle shaped tumor cells with marked pleomorphism and atypia (H\&E $\times 20)$, indicating undifferentiated sarcoma

considered, which led to great challenge for both surgery and repeated interventional procedure. But in our opinion, even with suitable stent choice, the malignant nature of the renal artery lesion must lead to recurrence sooner or later.

RAA caused by malignancies had been reported in the literature. A giant RAA caused by malignant solitary fibrous tumor of the renal vein was described by Hertz AM et al. [6]. RAA caused by sarcoma had also been reported $[4,5]$. The possibility that the coincidental association between the aneurysm and undifferentiated sarcoma could not be totally excluded, which was a great limitation for this case.

Sarcoma of arteries are rare and most frequently seen in elastic arteries, they are typically intraluminal, and have a variety of clinical presentations, while are rarely suspected clinically [4]. The tumor had aggressive behavior, showing evidence of distant metastasis [4]. All the above characteristics were consistent with our case. Unfortunately, no direct biopsy or pathological exam from the renal artery was available, but malignancy was still the most likely etiology behind recurrent RAA in this case. The prognosis of this case would be greatly improved if the operators had thought twice or proposed surgery before the stent insertion, since there was no solid evidence of Takayasu arteritis. After all, definite diagnosis is mandatory for interventional radiologists before stent insertion for treatment of RAA. This case highlights the potential that malignancy should be excluded in the diagnosis of aneurysm without obvious evidence supporting benign etiologies.

\section{Abbreviations}

CT: Computed tomography; RAA: Renal artery aneurysm

\section{Acknowledgements}

The offer of follow up information by Er-wei Zhang, Department of Urinary Surgery, the 1st Affiliated Hospital of Zhengzhou University, Zhengzhou, Henan, is greatly appreciated.
Authors' contributions

JZ, PZ, LW, YW, KG, QH and XW have all made substantial contributions to conception, acquisition of data, analysis and interpretation of data. All of them have been involved in drafting the manuscript and revising for the content. All authors read and approved the final manuscript and take public responsibility for appropriate portions of the content and agreed to be accountable for all aspects of work.

\section{Funding}

This case report did not receive any specific grant from funding agencies in the public, commercial, or not-for-profit sectors.

Availability of data and materials

Not applicable.

Ethics approval and consent to participate

Not applicable.

\section{Consent for publication}

Written informed consent was obtained from the participants for publication of this article and any accompanying images. A copy of the written consent is available for review by the Editor of this article.

\section{Competing interests}

The authors declare that they have no competing interests.

\section{Author details}

${ }^{1}$ Department of Urinary Surgery, Beijing Chaoyang Hospital, Capital Medical University, Beijing, China. ${ }^{2}$ Department of Interventional Radiology, Beijing Chaoyang Hospital, Capital Medical University, Beijing, China. ${ }^{3}$ Department of Pathology, the 1st Affiliated Hospital of Zhengzhou University, Zhengzhou, Henan, China.

Received: 11 July 2019 Accepted: 10 October 2019

Published online: 26 October 2019

\section{References}

1. Henke PK, Cardneau JD, Welling TH, et al. Renal artery aneurysms: a 35-year clinical experience with 252 aneurysms in 168 patients. Ann Surg. 2001;234: 454-62.

2. Gutta R, Lopes J, Flinn WR, Neschis DG. Endovascular embolization of a giant renal artery aneurysm with preservation of renal parenchyma. Angiology. 2008;59(2):240-3.

3. Tsilimparis N, Reeves JG, Dayama A, Perez SD, Debus ES, Ricotta JJ 2nd. Endovascular vs open repair of renal artery aneurysms: outcomes of repair and long-term renal function. J Am Coll Surg. 2013;217(2):263-9.

4. Staats P, Tavora F, Burke AP. Intimal sarcomas of the aorta and iliofemoral arteries: a clinicopathological study of 26 cases. Pathology. 2014;46(7):596603. 
5. Sachpekidis C, Langer R, Kollàr A, Wartenberg J. Detection of a primary tumor in the area of the renal artery with 18F-FDG PET/CT in a patient with metastatic undifferentiated sarcoma and a history of mid-aortic syndrome: a case report. Medicine (Baltimore). 2016:95(34):e4622.

6. Hertz AM, Childers CK, Wingate JT, Perry JT, Kitley CA, Brand TC, Anderson M. Malignant solitary fibrous tumor of the renal vein presenting as a giant renal artery aneurysm: a case report and review of literature. Int I Surg Pathol. 2019;27(1):72-6.

\section{Publisher's Note}

Springer Nature remains neutral with regard to jurisdictional claims in published maps and institutional affiliations.

Ready to submit your research? Choose BMC and benefit from:

- fast, convenient online submission

- thorough peer review by experienced researchers in your field

- rapid publication on acceptance

- support for research data, including large and complex data types

- gold Open Access which fosters wider collaboration and increased citations

- maximum visibility for your research: over $100 \mathrm{M}$ website views per year

At $B M C$, research is always in progress.

Learn more biomedcentral.com/submissions 